\title{
A flash-based on-the-job training game
}

\section{Eduardo Werneck and Maiga Chang*}

School of Computing and Information Systems, Athabasca University, 1 University Drive Athabasca, AB T9S 3A3 Canada, USA

E-mail: eduardo_d_werneck@yahoo.com

E-mail: maiga@ms2.hinet.net

*Corresponding author

\begin{abstract}
Most of research results show that the educational games are good to increase student's learning motivation in formal learning. This research reveals the project of designing and implementing a web-based educational game within a real corporate environment. It is amazing to find that what a real world company looks for is such a small and simple game. The game has been approved by the officer and used to provide to phone and face-to-face sales who have no minimum necessary knowledge of selling watercrafts insurance and have interest in using game-based learning mode instead of traditional PowerPoint presentation mode. The results show that the game mode's dispersion is quite high, showing a more volatile situation. Good news is, although the employees did not like the game itself, they are still willing to try the game, instead of the presentation, if offered.
\end{abstract}

Keywords: game-based learning; training; joy; computer game; educational games.

Reference to this paper should be made as follows: Werneck, E. and Chang, M. (2013) 'A flash-based on-the-job training game', Int. J. Arts and Technology, Vol. 6, No. 3, pp.229-245.

Biographical notes: Eduardo Werneck is a graduate student in the School of Computing Information and Systems, Athabasca University (AU), Athabasca, Alberta, Canada.

Maiga Chang's researches mainly focus on mobile learning and ubiquitous learning, game-based learning, educational robots, learning behaviour analysis, data mining, and intelligent agent technology. He serves several peer-reviewed journals as editorial board member. He has participated in 173 international conferences/workshops as a program committee member and has (co-)authored more than 158 edited books, book chapters, journal and international conference papers. In September 2004, he received the 2004 Young Researcher Award in Advanced Learning Technologies from the IEEE Technical Committee on Learning Technology. He is a valued IEEE member for 14 years and also a member of ACM, AAAI, and INNS. 


\section{Introduction}

Companies across the globe are using a combination of online delivery training and traditional classroom instructor delivery, in order to respond their current needs. The online delivery looks like a regular Microsoft PowerPoint presentation, but now updated to tools like Adobe Captivate, which provides some animation, as well as quiz capabilities.

Game learning is a hot topic. Pailing (2002), mentions e-learning into the training market as still a young and confused player, but states e-learning would be a $\$ 6$ billion industry in Europe, by 2005. Derman (2000) says the US e-learning market was worth $\$ 17.2$ billion in 1999. These figures reflect the incentive developers, academics, investors and media have to look into this market with the attention it deserves. Some researchers point out that playing can hold student attentions and make learning be more interesting (Boyle, 1997; Lin and Liu, 2009; Virvou et al., 2005). For this reason, many studies use commercial games directly or design new education games and have evidences of students can get significant improvement in learning (Anderson et al., 2008; Chiang et al., 2011; Steinman and Blastos, 2002; Šisler and Brom, 2008; Virvou et al., 2005).

Several studies have been carried out on game-based learning with an educational orientation, especially for a possible use in either helping learning the traditional classroom environment, or supporting teaching activities (Hsiao, 2007), with improving techniques like the multi level challenge system (Cheng et al., 2007). Other game-based learning systems were, for examples, VISOLE (Shang et al., 2007), AnswerMatching (Wu et al., 2007), Shadow Box (Sung et al., 2007), and Simulation Fish Tank (Tan and Biswas, 2007). The literature covers developments in the e-learning research from the military to the classroom, but this is a fairly young subject, which has been following the personal computer revolution and received a super vitamin boost with the latest internet broadband improvements.

The uniqueness of this study is the fact that it is a test in a real corporate environment (comparing the current training already successfully applied to employees), and the training format is based on a combination of the current chart presentation, but adding a game component. The two fundamental questions to understand the success of this training are:

- How effective was the game-based learning compared to the current format used by the company?

- How engaged were the employees, also compared to the current format?

If a game format is tested against the current used format and the post-test results are favourable and statistically significant for the game, it would be considered effective. As for the engagement, if applying an after test questionnaire to quantitatively measure the engagement also contributes to a favourable and statistically significant result for the game, it would be considered as an engaging tool.

Ahdell and Andresen (2001) explore the corporate training problem and how games and simulations are being used in companies in North America and Nordic countries. They found engagement as the main benefit a game can bring to the corporate scenario, as it would make the presentation of information less boring: have fun while learning. The authors also mentioned effectiveness as the main challenge due to the lack of data available to measure the effects of different methods of training. 
This research also tries to understand the impact gender and age group may have on both formats:

- Is game more associated to men, than women?

- Are younger generations more inclined to choose game as a learning tool, than older generations?

It does not mean these two secondary questions should deviate the focus of this study; however it may help to explain possible behaviours.

This paper describes a flash-based on-the-job training game for teaching a mix of phone sales and face-to-face sales in R-Company boating regulation and insurance policy. This paper is organised into three sections, Section 2 talks the game itself and Section 3 reveals the experiment and questionnaire design. Section 4 discusses the collected data and the findings and Section 5 concludes this research.

\section{The game}

The process of recruiting a company willing to allow its employees to participate in an academic empiric research is not an easy task, when the subject of the study is game-learning. Armed with a mini-proposal and a sales plan explaining the benefits for an organisation to help out with an academic study was not enough (Werneck and Chang, 2009). The word game represents a major road blocker, even after carefully explaining factual information regarding peer review studies showing game-learning systems as a powerful and effective learning tool.

The initial prototype was quite different from the final version of the game, basically due to the several changes initiated by the company. The involved employees take the project as something produced by their own department, and not an academic project. It was quite usual to receive a request to modify something related to the game, and not the training content itself (Werneck and Chang, 2009). This rest of this section describes the game and its mechanics, showing the details of how to play it and visually explaining all the steps of the tool.

The idea was to have a presentation style training embedded in a board game. In order to cut production and development time, the game was developed in Flash CS3, using ActionScript 2 in an Apple Macbook Pro $2.5 \mathrm{GHz}$ with 4 GB memory. A prototype was initially designed and sent to the learning and development team of R-Company and evolved in the final game shown below. Without going into details, a brief description of the game mechanics is described below.

Figure 1 shows the screenshot of the game, with the presentation panel at the top left hand side with the pagination on the top right of the frame, the path for the sailing boat in dash style at the right hand side, plotted around the island, with pirate flags as part of the path. There is a start and finish lines, as in a boat race, at the bottom of the screen and the sailing boat parked at the start line. The finish line is a treasure ' $x$ '. The green die with the button roll is at the bottom left hand side and right beside, on the right, is the points panel, with the two shark fins beside it. The shark fins are used to navigate through the presentation panel (back and forward). There are some props used in the game for 
ornamental purposes only, like the light-house, the anchor and the island, but they do not have any function, neither feature associated.

Figure 1 Game mechanics - how to move through the game (see online version for colours)

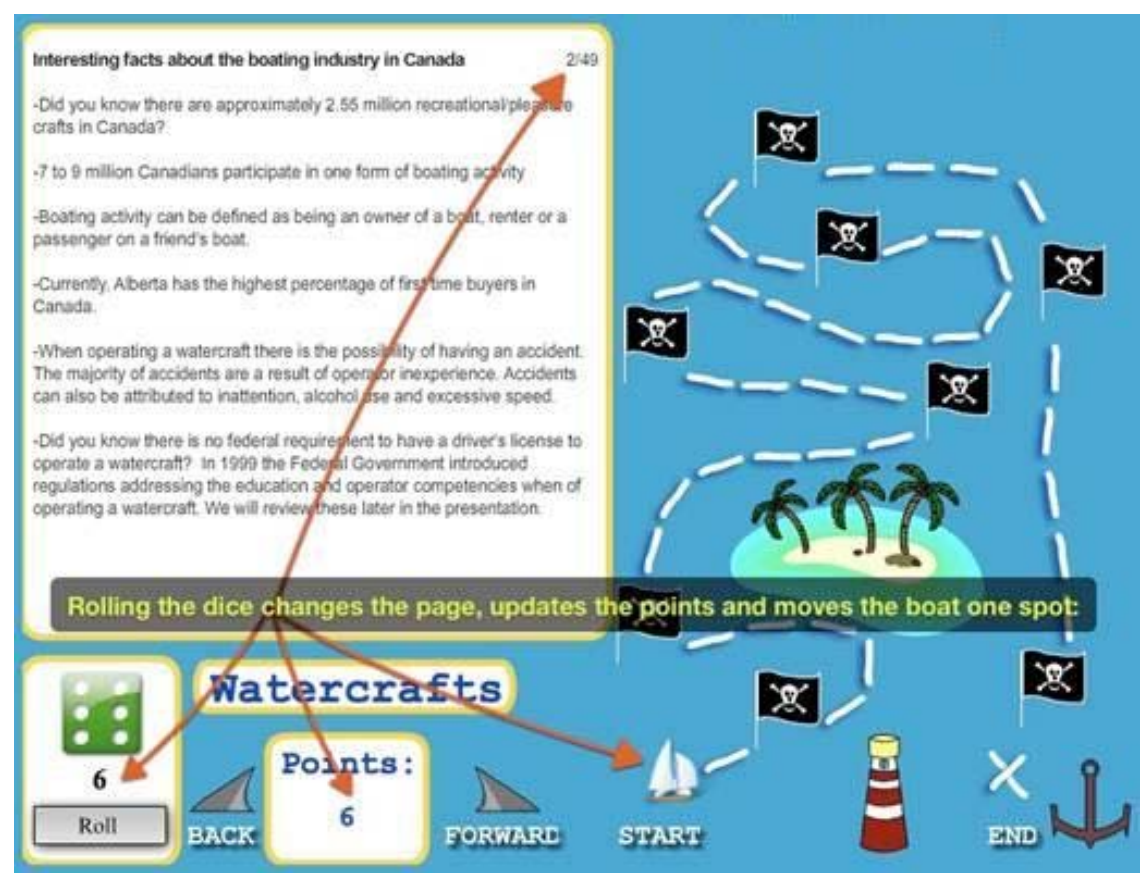

In order to start playing, the employee has to click in the button named roll, which will roll the dice, giving a number from 1 to 6 . This number is going to update the points box, advance one chart in the presentation panel and no matter what number the employee rolled out, the sailing boat moves one spot (or dash) at a time. At any spots, except the pirate flags, the presentation panel will show the employee the important knowledge of boating industry and insurance policy. The points the employee receives at the end of the game currently is only for fun and s/he may compete with each others to see who has better lucky. There is 'win' situation, but there is a scoring through points, so the objective of the game itself is to score as much points, as possible.

In order to bring up excitement, a challenging situation was created through the pirate flags: every time the boat moves to one of these $8 \mathrm{flags}$, the presentation panel will bring up a quiz, which has to be answered by clicking in the true, or false button: without selecting an answer, the game does not go on and the sailing boat will be stationary in the current position, with the roll button deactivated, as seen in Figure 2. The questions used in this quiz are exactly the same used for the pre-test, however, they were positioned after the corresponded charts teaching the respective subject. The use of the quiz was supposed to help with the engagement, at the same time as it would help in understanding the lessons and improving the learning process.

If the player answers the question correctly, an applause sound will play and the one hundred extra points are granted, as seen in Figure 3, then the roll button will be active again as shown in Figure 4. 
Figure 2 The quiz process (see online version for colours)

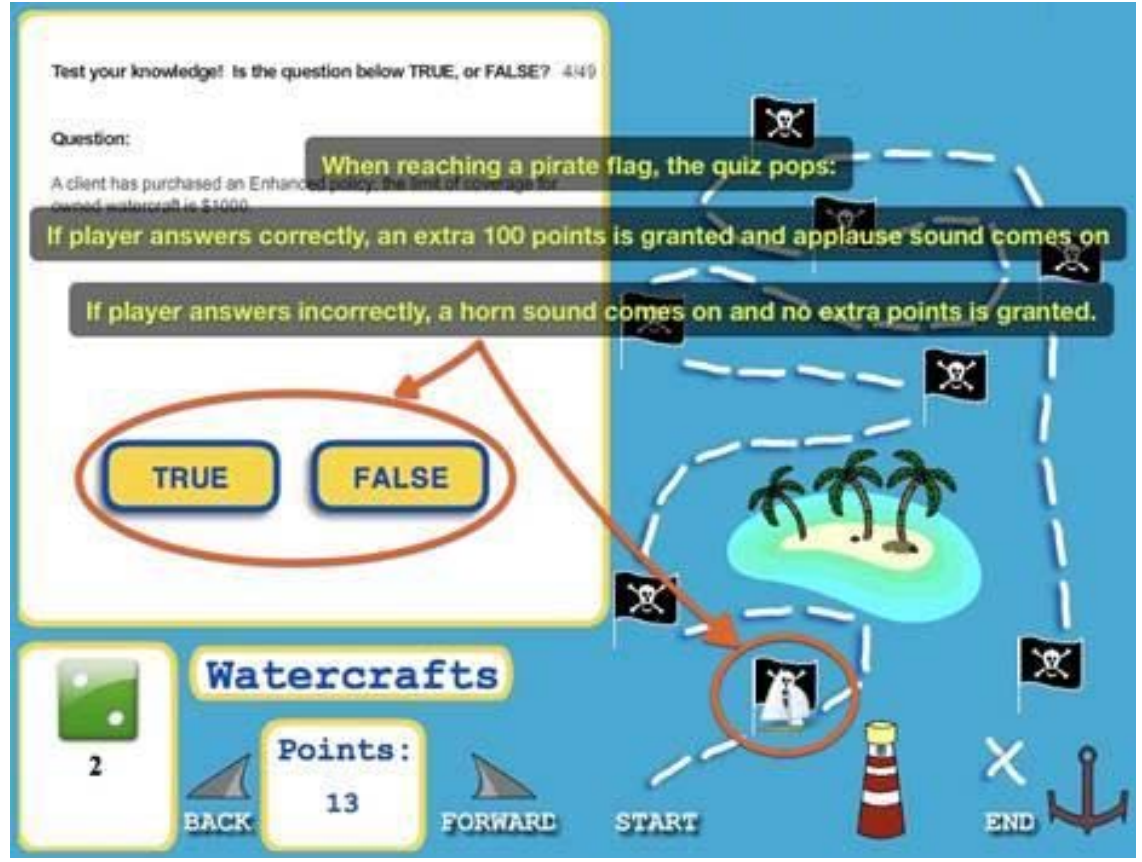

Figure 3 Extra 100 points granted (see online version for colours)

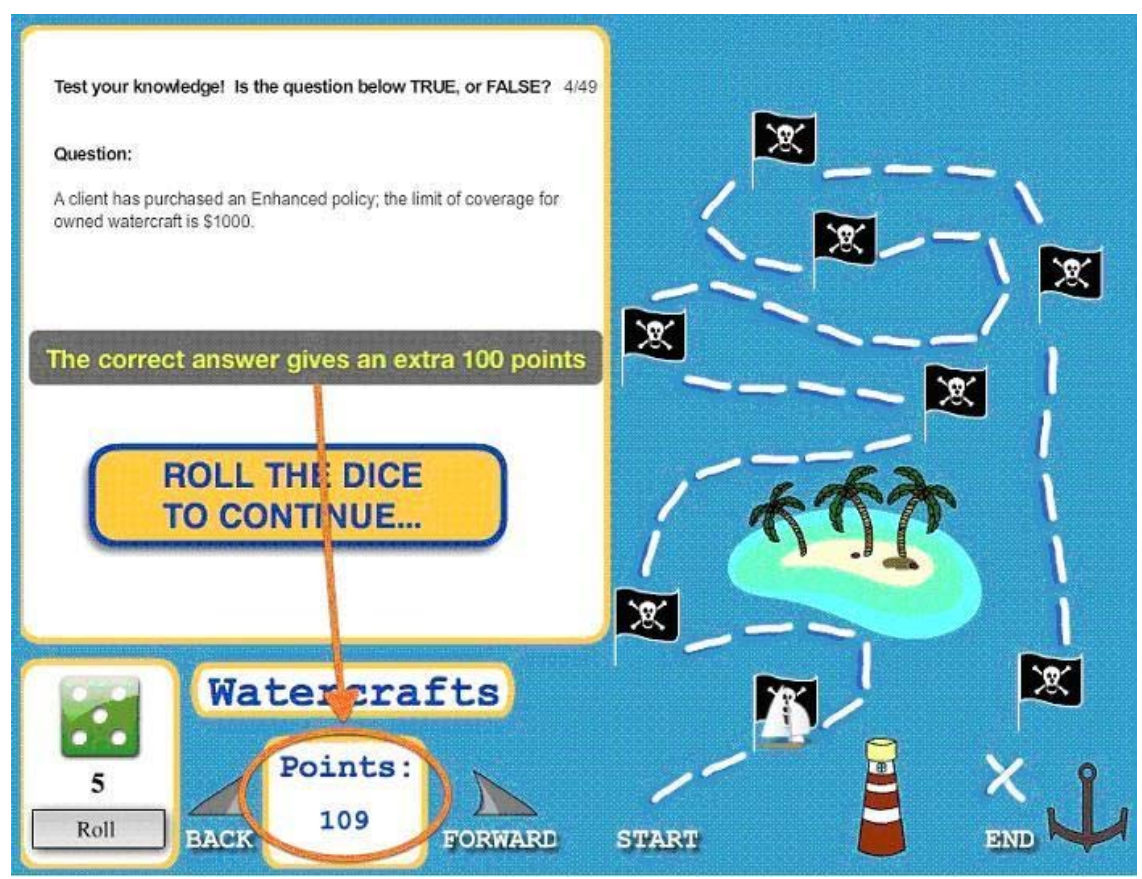


Figure 4 Roll the dice button is active again (see online version for colours)

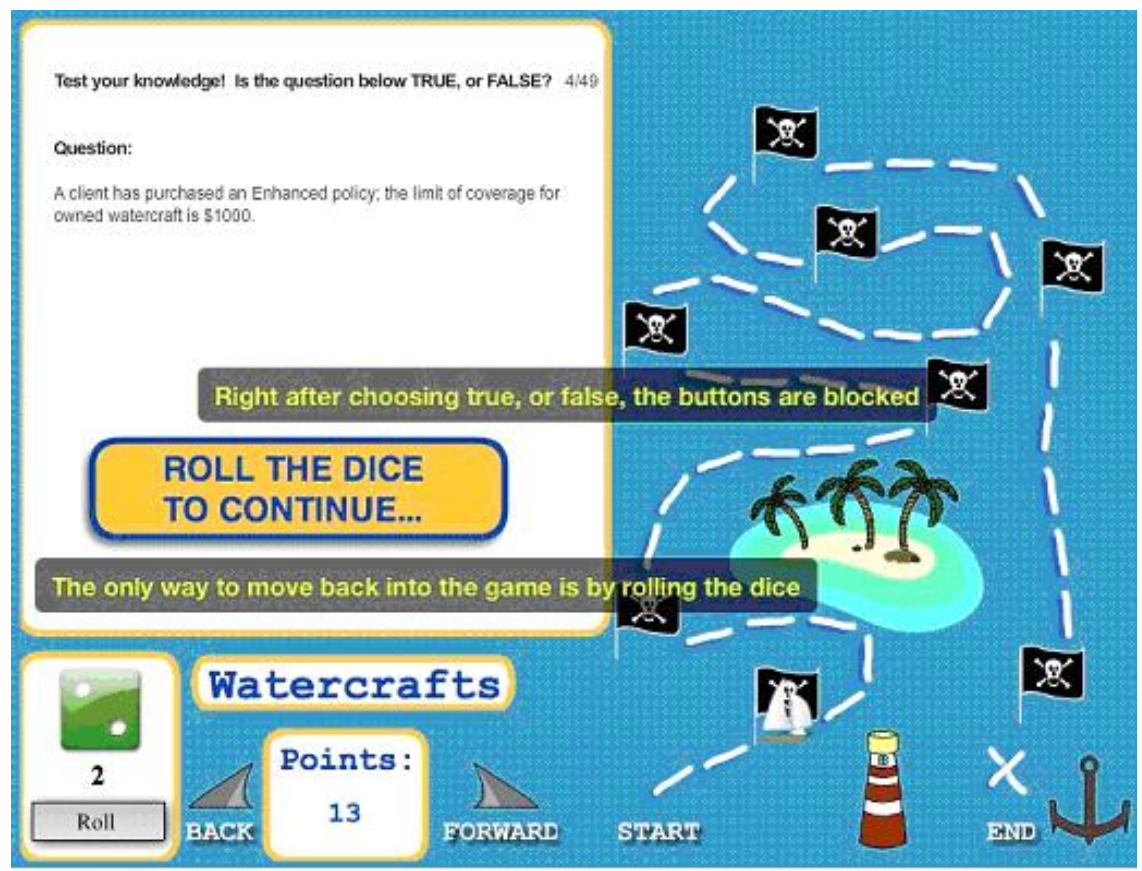

Figure 5 Presentation panel illustration and pictures (see online version for colours)

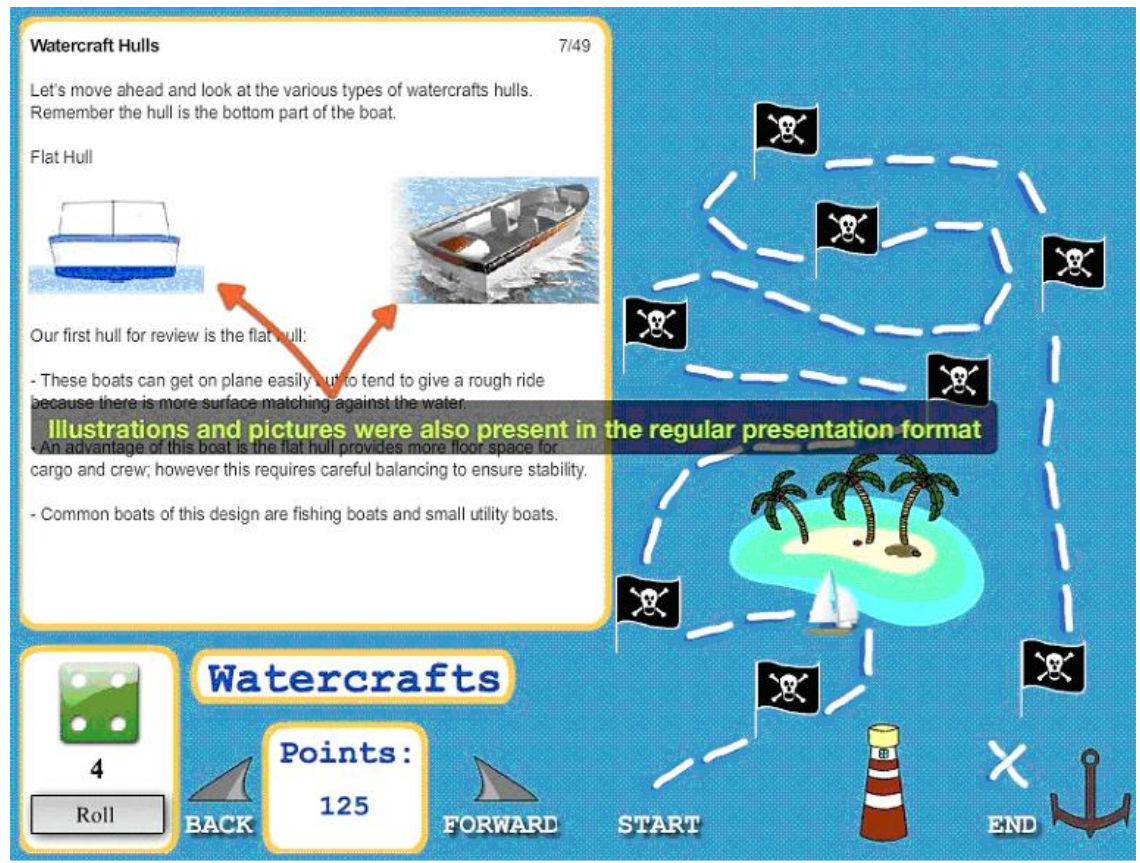


If the wrong answer is selected, the sound played will be of a horn, no points will be granted and the roll button will be activated. The pictures and illustrations present in the current presentation format were also replicated in the game presentation panel, as per Figure 5 , in order to guarantee there would be a fair comparison between both delivery formats.

The game will end when the boat reaches the ' $x$ ', coinciding with the last presentation chart, which is number 49. At this moment, a voice saying 'job well done' will play, the presentation chart in the presentation panel will inform the player about the end of the training and ask them to either play the game again, or to go to their post-test questions posted at the training portal.

\section{Experiment flow and questionnaire}

The evaluation process starts with the pre-test of employees who need to have some skill set addressed in the training, and ends at the post-test to verify if the employee achieved minimum necessary knowledge after the training. If the employee does not achieve minimum required score for the pre-test, the employee needs to be exposed to the watercrafts training module, in order to sell watercrafts insurance.

Figure 6 Research flow chart from the development phase to the research questionnaire (see online version for colours)

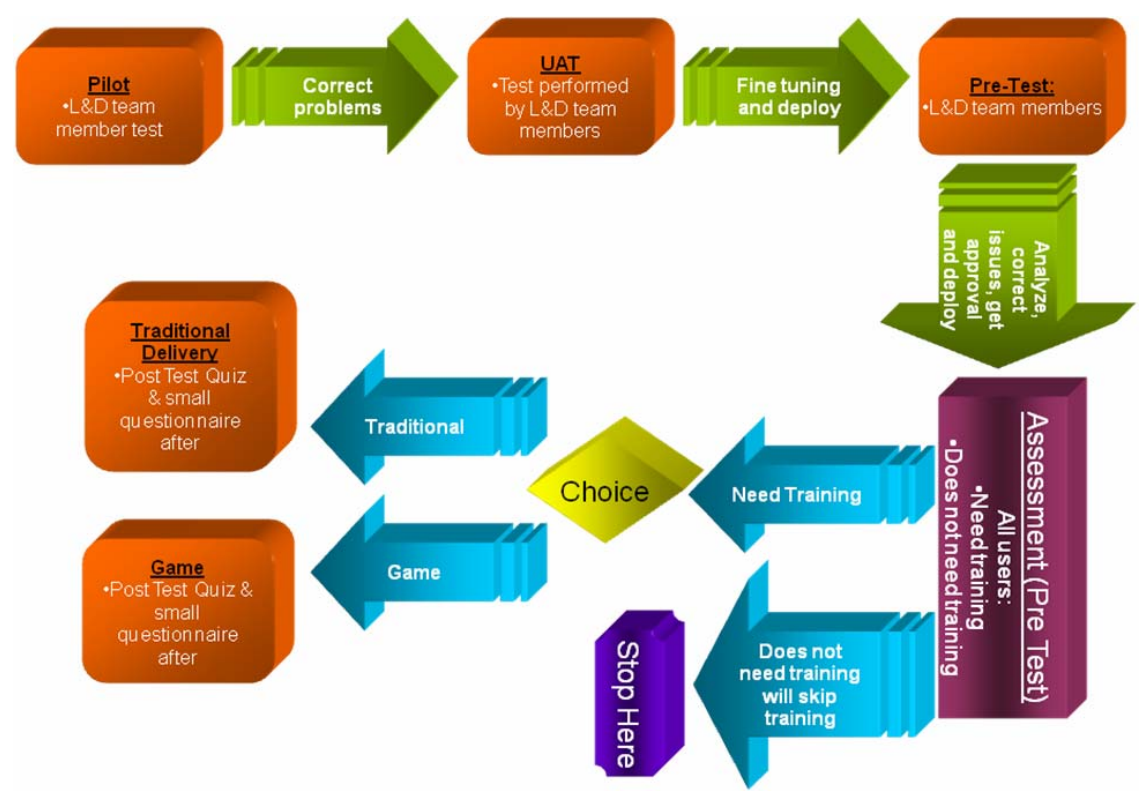

The R-Company was delivering the training through electronic format, as a Microsoft PowerPoint presentation, however through Adobe Captivate, where it is possible to include voice. Once the employees finished the training, they have to sign in the training portal and complete the post-test, which is again, conditioned to the minimum score: if they fail, they have to re-do the training. 
For this study, we plan to accommodate the game-learning tool as an option the employee should decide about: this measure would help in capturing the interest in the game format. The target of this evaluation plan is a mix of phone sales and face-to-face sales taking watercrafts knowledge and insurance selling training. Not all participants will use the game for training, the actual number of participants may vary depends on their pre-test performances and training mode preferences. Although we can not expect how many participants we will have due to they are screening by a pre-test first and the remains have option to take presentation-based training instead of game-based training, at least it is a real world project, which would show the results based on real life experience.

Figure 7 The voluntary six-item questionnaire

1. Enter your score on the post test:

2. Gender: |_| Male |_| Female

3. Age:

I_l between 18 to 30 years old

I_l between 31 to 40 years old

I_ between 41 to 50 years old

I_l over 51 years old

4. Why did you choose this delivery mode (chose one of the first 4 questions if you chose the game, or the latest 4 if you chose the presentation):

I I if you chose the game: did you choose it because you were curious to see what it was about?

I_ if you chose the game: did you choose it because you wanted to have more fun?

I_l if you chose the game: did you choose it because you are used to play games?

I_l if you chose the game: did you just choose it by chance?

I_l if you chose the presentation: did you choose it because you do not like games?

I_l if you chose the presentation: did you choose it because you believe the game is distractive to learn?

I_l if you chose the presentation: did you choose it because you are not used to play games?

I_l if you chose the presentation: did you choose it by chance?

5. In a scale from 0 to 5 ( 5 being the highest) chose the number which best describes how much you prefer this delivery method than the other option available:

I_ $1\left|\_\right| 2\left|\_\right| 3 \mid$ | $4\left|\_\right| 5$

6. In a scale from 0 to 5 ( 5 the highest) chose the number which best corresponds to your willingness to chose a game, next time you have it available for another training:

I_ $1\left|\_\right| 2\left|\_\right| 3|+4| \_\mid 5$ 
At the end of the process, a voluntary six-item questionnaire as Figure 7 shows is provided to the participants. The questionnaire is used to understand how the game was perceived by the people who chose the game, or the regular delivery format. Again, the reason of using this short questionnaire instead of 10 - or 20-item questionnaire is fitting into the original on-the-job training process R-Company has, it turns out that we only have space for six items. Moreover, due to the information privacy protection rules, the questionnaire spends four items to gather participant's personal information includes post-test score, age, gender, and training mode s/he chose. We design the remained two items to ask the participant's perception towards the game-based training mode.

\section{Results and discussion}

One day after the end of the training, which was April 1st, the results started to come: 32 participants. As the initial estimate of employees taking the training was around 240, another set of e-mails started to be exchanged. Only after a phone call it was possible to understand why only a fraction of the participants took the training: it was offered to 80 participants only. From these 80, 48 passed the pre-test and did not need to do the training. Although it was unexpected that such a small amount of people would do this module, at least it was a real world project, which would show the results based on real life experience.

From the 80 employees in the department, 32 completed the training. From these 32, 23 responded the questionnaire. From these 23, 2 answers will have to be discharged, as the score is clearly incorrect: they show a score of 8 , and 9 , which is way too low compared to the rest of the answers (between 45 and 100).

Table 1 shows a picture of the funnel and the first noticeable fact: the majority $(62 \%)$ still preferred the current presentation format over the game. The game did not attract more people, as a fact. It is important to highlight how the employees were exposed to their options: an e-mail was sent to communicate they would be offered a choice of the regular training and the game-learning version, and they were pointed to the company's intranet portal's training micro site, where the options were available. The employees were also requested to fill out the questionnaire for this study on a voluntary and anonymous basis, which means there was no possibility to link the pre-test, post-test and the answers from the questionnaire.

Table 1 Overall training funnel

\begin{tabular}{lccc}
\hline Employees & Quantity & Percentage over the total & $\begin{array}{c}\text { Percentage over } \\
\text { good respondents }\end{array}$ \\
\hline Total & 80 & $100 \%$ & N/A \\
Had to take training & 32 & $40 \%$ & N/A \\
Responded questionnaire & 23 & $29 \%$ & N/A \\
After discharging bad data & 21 & $21 \%$ & $100 \%$ \\
Presentation mode & 13 & $16 \%$ & $62 \%$ \\
Game mode & 8 & $10 \%$ & $38 \%$ \\
\hline
\end{tabular}


The questions were posted at the company's portal, through their automated scoring system and therefore, it had to respect the format required by the R-Company. One of the hypotheses this study would like to test was how gender would influence the choice towards the game-learning options. The media has been showing signs for women increasingly moving into the video game scene, as per Dumitrescu (2009), referencing a study from AC Nielsen from April 2009, showing that more than $50 \%$ of video games players are women, or the article published at the Canadian Broadcasting Corporation (2006), showing women outnumbering men in online games.

Digging deeper into some gender myth, as the sample was somehow balanced between males and females, the research found that the overwhelming majority $(87.5 \%)$ of the employees who took the game were women and only $12.5 \%$ were men, who preferred the presentation format, compared to women, as show in Table 2. These results are not conclusive that women prefer game-learning, compared to men, but it opens the door for further research about this subject, especially considering the improvement in the average score from $73 \%$ to $78 \%$ in the game group, when we focus in the female subgroup. The hypothesis has been confirmed, as women did prefer the game.

Table 2 Gender distribution

\begin{tabular}{lccc}
\hline Distribution & Female & Male & Total \\
\hline Total respondents & $57 \%(12)$ & $43 \%(9)$ & $100 \%(21)$ \\
Presentation mode & $38 \%(5)$ & $62 \%(8)$ & $100 \%(13)$ \\
Game mode & $88 \%(7)$ & $13 \%(1)$ & $100 \%(08)$ \\
\hline
\end{tabular}

The age distribution of the sample was skewed towards the younger bracket of 18 to 30 years old, however this myth holds through: the concentration of people who prefer the game format was heavily concentrated within the 18 to 30 years old bracket, as per Table 3.

Table 3 Age distribution

\begin{tabular}{lccccc}
\hline Age group & 18 to 30 & 31 to 40 & 41 to 50 & Over 51 & Total \\
\hline Total respondents & $62 \%(13)$ & $29 \%(6)$ & $0 \%(0)$ & $10 \%(2)$ & $100 \%(21)$ \\
Presentation mode & $46 \%(6)$ & $38 \%(5)$ & $0 \%(0)$ & $15 \%(2)$ & $100 \%(13)$ \\
Game mode & $88 \%(7)$ & $13 \%(1)$ & $0 \%(0)$ & $0 \%(0)$ & $100 \%(08)$ \\
\hline
\end{tabular}

The key fact which makes age an important variable for this game-learning study is the correlation between age group and format: the average age for the group which chose game is 26 years old, while the average age for the group which chose the presentation is 33 years old, making the demographics for the game-learning format as younger women.

Figure 8 shows the correlation of age in the samples. Being the horizontal axis the score obtained and the vertical axis the average ages of the individuals, and the size of the bubbles the amount of people, it is possible to visualise how the presentation and the game population are distributed. Clearly, the game-learning has lower bubbles, showing the younger players, in contrast with the presentation, with higher bubbles. The same way, we can see how the bubbles from the presentation group is positioned more to the right, representing the better scores achieved. 
Figure 8 The importance of age (see online version for colours)

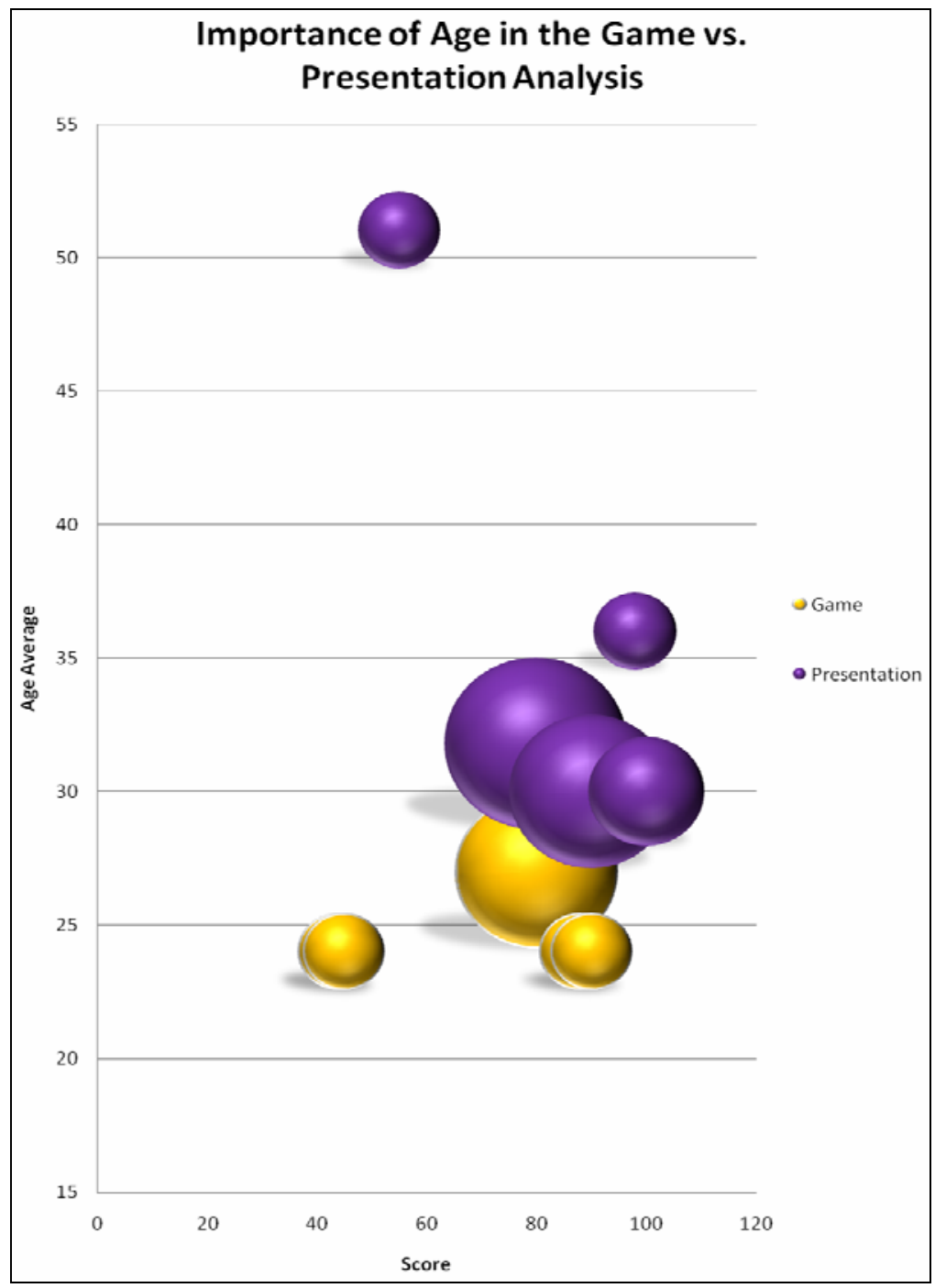

It is important to reinforce that the questionnaire was not mandatory and there is a possibility of shifting this sample, but even applying the remainder ten participants who did not answer the questionnaire, to the presentation format younger bracket, it would move it to $69 \%$ participation, which is still lower than the game format. Therefore, age played a definitive influential role in choosing the game format.

Concentrating in the core questions about the effectiveness and engagement of the game compared to the presentation, the results were not satisfactory for the game format. Briefly going through the 21 scores for the respondents, we have the results in Figure 9, where the mean was 80.95 . Nine respondents achieved $80 \%$, which was the most frequent score and also the minimum required to pass the test. The three respondents who failed and received scores $40 \%$ and $50 \%$, failed. 
Figure 9 Summary results for total respondents (see online version for colours)

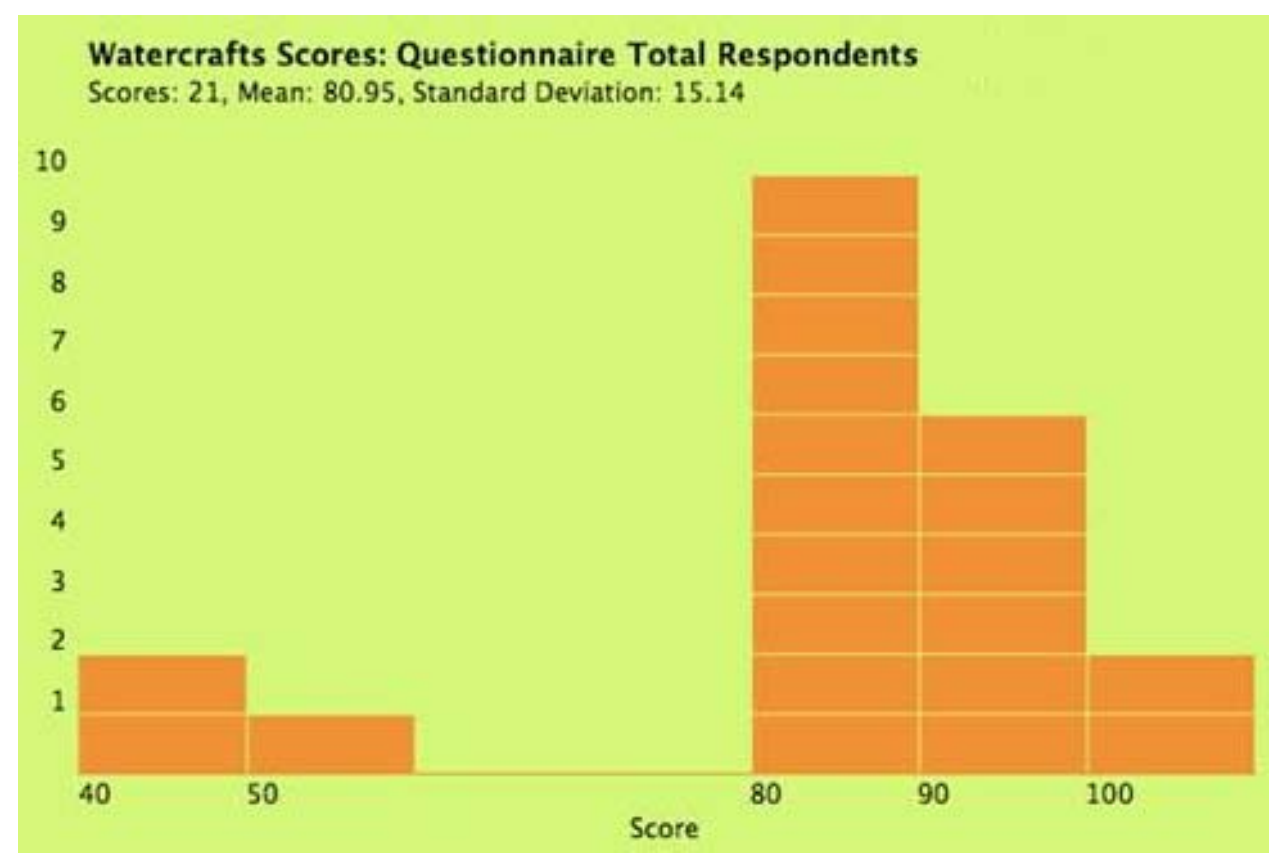

Figures 10 and 11 show the summaries for the presentation format and game format respectively. The impressive result for the presentation format was quite surprising: a mean of 85.62 against the game mean of 73.38 , or almost $17 \%$ higher than the game. However, the worst part is the standard deviation, the standard deviation of the presentation mode (11.57) is better than that of the game mode (17.08). The game lowest score was 40, against 50 for the presentation. The maximum score for the presentation was 100, against 90 for the game. Also, the concentration of 90's and 100's was greater in the presentation. Two individuals who chose the presentation format failed, as per Figure 10, but four failed the game, which is proportionally higher than the presentation. The rest of the questionnaire became extremely important in order to explain why these results do not match what was originally expected, showing the game not effective as the presentation format and clearly questionable as a training tool.

When analysing the responses from the presentation mode group of employees, it shows they had a higher mean than the game mode, as we can see at Table 4, and it shows the presentation as achieving a higher preference than the game. The game did not appeal to population who chose it. It shows that the employees who chose the game, did not like it, therefore, a contribution to the lack of engagement.

The median represents the higher half of the sample. Again, the presentation has a median of 4 , against 3.5 from the game, confirming the population which chose the presentation liked better than the game. However, the mode, which is the value occurring more frequently, is higher for the game: five against four, confirming the standard error, and the standard deviation, both very high for the game. The variance, which is another measure of statistical dispersion, is again higher for the game and when putting everything together, the picture turns into a better consistence for the presentation, which not only achieved higher marks in preference, but it had a lower dispersion of the sample. 
The game, on the other hand, was not as liked as the presentation and the dispersion was quite high, showing a more volatile situation.

Figure 10 Summary results for presentation mode respondents (see online version for colours)

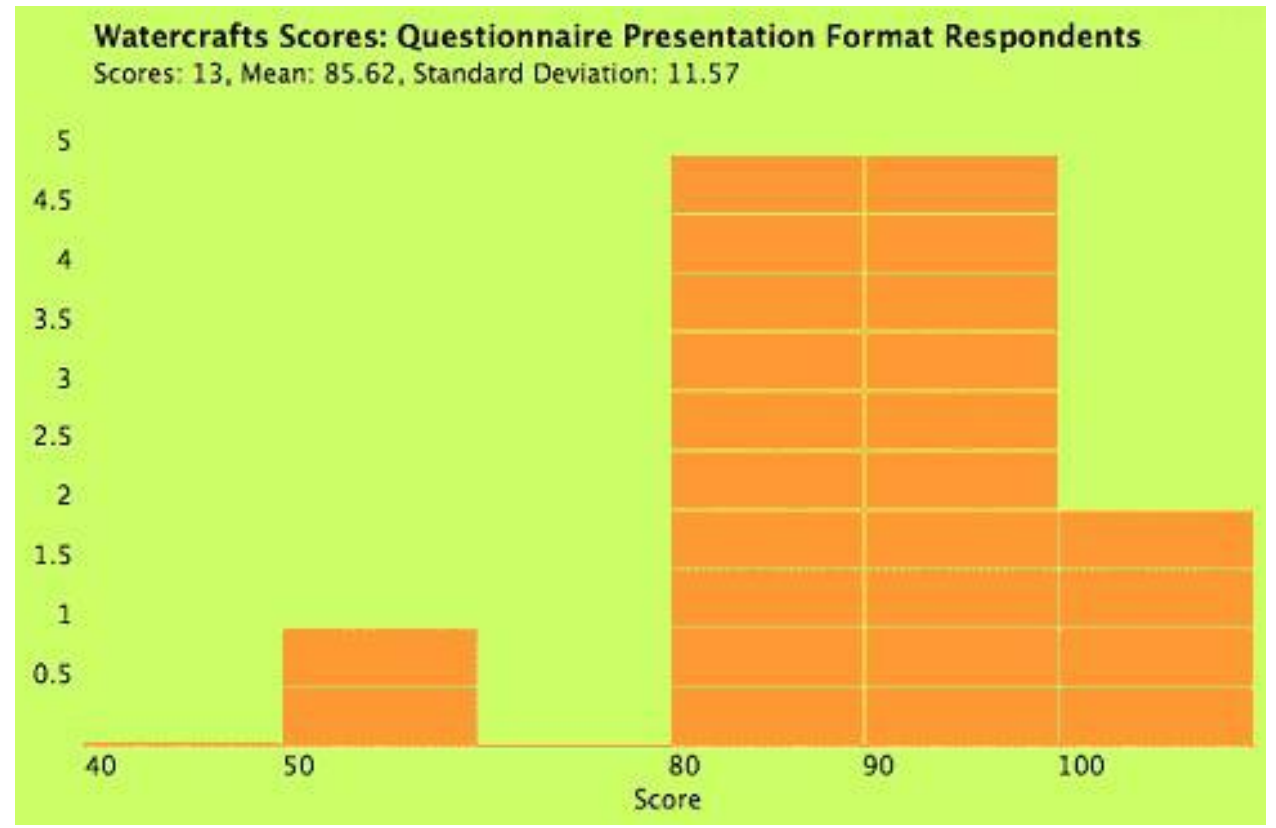

Figure 11 Summary results for game mode respondents (see online version for colours)

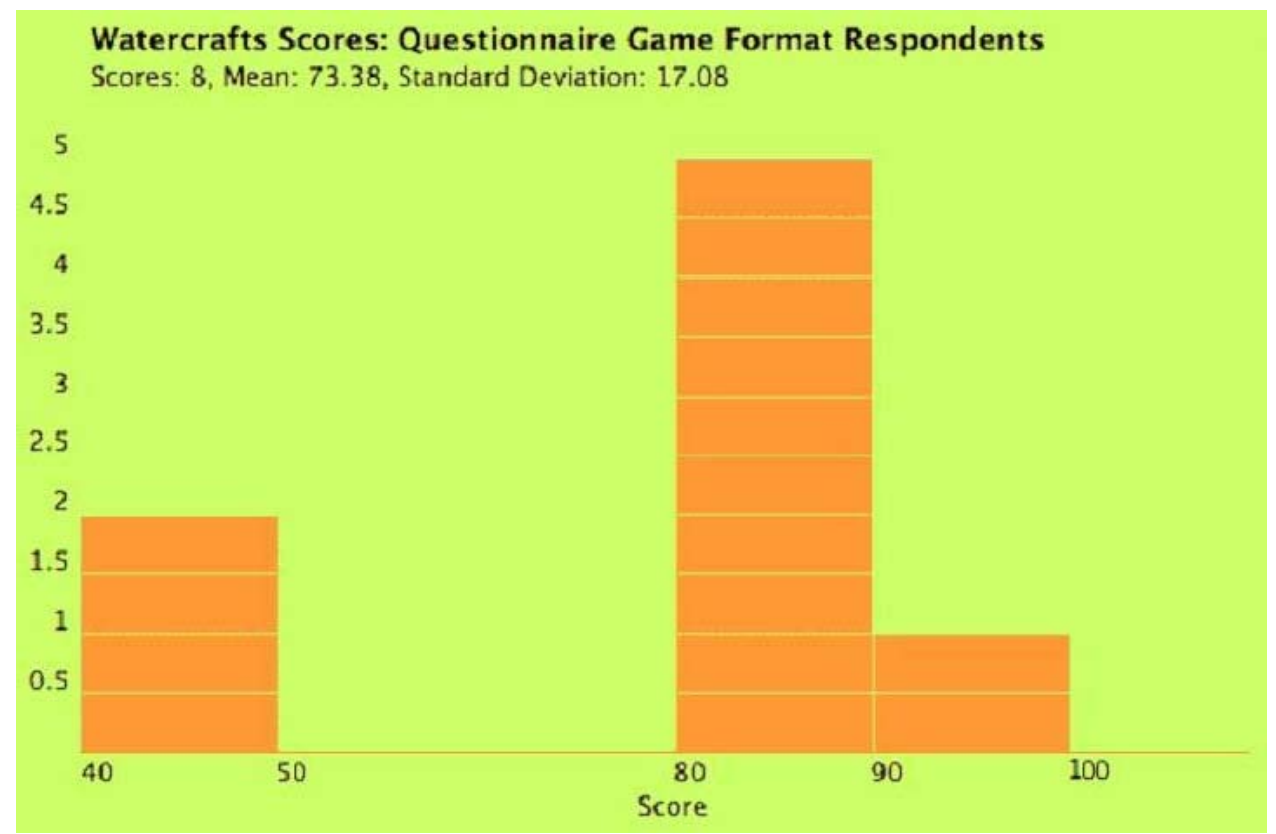


Table 4 Descriptive statistics for how much the employees like the current training

\begin{tabular}{lcc}
\hline Mode & Presentation & Game \\
\hline Mean & 3.92 & 3.25 \\
Standard error & 0.26 & 0.56 \\
Standard deviation & 0.95 & 1.58 \\
Variance & 0.91 & 2.5 \\
Median & 4 & 3.5 \\
Mode & 4 & 5 \\
\hline
\end{tabular}

Now comparing the statistics for the question if they prefer a game, the results surprisingly change to what we see in Table 5, where the mean for the game group shows they still prefer the game and the overall statistics drastically changes towards the game. The mean is higher for the game, the median and mode are higher, showing the dispersion significantly improved, although both the standard error and standard deviations are higher, but not as high as the previous question:

Table 5 Descriptive statistics for how much the employees would choose game next time

\begin{tabular}{lcc}
\hline Mode & Presentation & Game \\
\hline Mean & 3.23 & 3.75 \\
Standard error & 0.43 & 0.62 \\
Standard deviation & 1.54 & 1.75 \\
Variance & 2.36 & 3.07 \\
Median & 4 & 4.5 \\
Mode & 4 & 5 \\
\hline
\end{tabular}

The lack of engagement came from the fact that the employees did not like the game, as per the statistics from Table 4, however it is necessary to expose a problem in the capture of the information from this question: somehow the spreadsheet received from the company, shows the results for this question split in two columns, instead of one. It was not possible to find out why it happened, but there is a possibility of misinterpretation of the question. On the other hand, if the statistics hold true, it means the employees did not like the game itself, but they are still willing to try the game, instead of the presentation, if offered. It shows the likelihood of a better engagement for the game and opens up the question of what happened in this situation: was the game performance related to the learning style of the target population?

Last but not least worth-to-mention finding here is, almost all participants in the game mode group are females, only one male participant in this group, which reflect the recent studies of the gender differences on the attitudes toward educational games (Ke, 2008; Lu et al., 2011; Papastergiou, 2009).

\section{Conclusions and future works}

The idea of a game component would help, did not hold through as it did not improve performance, neither brought engagement. Academic studies like VISOLE (Shang et al., 2007), AnswerMatching (Wu et al., 2007), Shadow Box (Sung et al., 2007), and 
Simulation Fish Tank (Tan and Biswas, 2007) proved to be successful within academic environment, but were never compared side by side within a corporate environment. Adhell and Adresen (2001) show case studies from companies like Electrolux, where game is used to train employees. However, there was no quantitative test in their study, but just a qualitative analysis, what reinforce the need to bring the game to the real life and keep on improving it until it eventually shows its value, as the military as mentioned in Capps et al. (2001).

Perhaps the most important suggestion is to follow more closely the Felder and Silverman (1988) learning and teaching models and make sure it will be covered more adequately. If just a game-learning tool does not show engagement, it may be distractive and undermine the training. In this case, if the learning style from Felder and Silverman is matched to the students understood behaviour, it would be more of a sensor, as they tend to like more facts, they are more connected to real facts and they are very good in memorising. Sensors would like the presentation style, as they prefer having the facts presented for memorisation, without the abstraction of the game. The studied population is definitely not visual learners, as the quiz introduced in the game, for example, would have helped the visual to go back to the question, move the shark fins back and forward to retrieve the question and answer it properly. However, they may be sequential learners, as the fact they had to throw the dice and stop for questions would disorient a sequential learner, who needs to build up from step to step. The population may have some active learners, who need to do something active with the information, while the reflective learner would have taken advantage of the game better, as the quiz brings the possibility of revise the material. However, Felder and Silverman mention the visual learners as the most representative in the general population, and this group responds better with written and verbal stimulation, especially with visual aids, like movies, flow-charts, pictures, timelines, demonstrations and although the charts in both the presentation and the game had visual stimulation, the game did not take advantage of the graphic design and animation capabilities enough, in order to make a difference from the presentation.

Although it is difficult to match the creative process of creating the game, to the corporate needs, this challenge has to be worked the same way as an advertising agency has to be creative at the same time it fulfils the requirements from the client. It is possible to overcome this challenge and create a more effective game.

Although there was not a positive result for the game, as the outcome was lower effectiveness and lack of engagement, it shows that the user did not like the game. Going back to Felder and Silverman (1988), this game touched just the presentation teaching style correctly, but failed to achieve content and organisation teaching styles. A flight simulator allows pilots to effectively train, if it engages. A simulation should be touching as much learning and teaching styles, as possible. In this game-learning tool, the addition of a game component without any relationship with the story being told, even though there were the pirate flags with the quiz and the luck aspect from rolling the dice, it did not captivate the marginal attention from the players. The challenge would be to work towards a simulation model and not just a game component, and re-test it. If a flight simulator is good enough for training pilots, there is light at the end of the tunnel.

Going through the hypothesis tested in this study, as well as the outcome of the research, some future research suggestions can be drawn: 
- Gender game-learning behaviours: how men and women respond to game-learning. Which differences are key to understand the behaviour and the results achieved from each group. Which kind of games are preferred by each group and what is the performance achieved by each gender, in each kind of game, as per engagement and scores?

- Gender game-learning learning styles preferences: how men and women are distributed into the learning styles and which game styles they prefer?

- Gender and age game-learning behaviours: how does age and gender behave towards game-learning? Is there any difference between age brackets for each gender?

- Learning styles mapping to game-learning styles: which kinds of game-learning styles are available and how do they map to the learning-styles?

Reading through this study there are definitely other researches the reader can creatively catch. However, if educators can understand the relationship between the learning styles, gender, age and game-styles and quantify the engagement and efficiency, the path to creating the best practices for game-learning and improving education would be well delineated.

Another important point is to make sure future studies consider some focus groups, or face-to-face interviews with employees, pre and post tests. These interviews would help to understand attitudes and behaviours, helping to better tune up the game to the training, focusing on the different learning styles from the sample interviewed group.

\section{References}

Ahdell, R. and Andresen, G. (2001) Games and Simulations in Workplace eLearning - How to Align eLearning Content with Learner Needs, Norwegian University of Science and Technology Department of Industrial Economics and Technology Management, available at http://www.twitchspeed.com/site/download/thesis_final.pdf (accessed on 20 February 2012).

Anderson, T.A.F., Reynolds, B.L., Yeh, X.P. and Huang, G.Z. (2008) 'Video games in the English as a foreign language classroom', DIGITEL 2008: Proceedings of the 2nd IEEE International Conference on Digital Games and Intelligent Toys Based Education, 17-19 November, Banff, Canada, pp.188-192.

Boyle, T. (1997) Design for Multimedia Learning, Prentice Hall, London.

Canadian Broadcasting Corporation (2006) Women Gaming Online Outnumber Men 2 to 1: Report, available at http://www.cbc.ca/news/story/2006/10/06/tech-womengamers-061006.html (accessed on 30 May 2012).

Capps, M., McDowell, P. and Zyda, M. (2001) 'A future for entertainment-defense research collaboration', IEEE Computer Graphics and Applications Journal, Vol. 21, No. 1, pp.37-43.

Chiang, Y-T., Lin, S-S.J., Cheng, C-Y. and Liu, E.Z-F. (2011) 'Exploring online game players' flow experiences and positive affect', Turkish Online Journal of Educational Technology, Vol. 10, No. 1, pp.106-114.

Cheng, H.N-H., Deng, Y-C., Chang, S-B. and Chan, T-W. (2007) 'Design of multi-level challenges of a digital classroom game', DIGITEL 2007: Proceedings of the 1st IEEE International Workshop on Digital Game and Intelligent Toy Enhanced Learning, 26-28 March, Jhongli, Taiwan, pp.11-18.

Derman, D.M., Parekh, M., Berquist, T.P., Elliot, C. and Chung, C.J. (2000) Internet: e-Learning United States, Goldman Sachs Global Equity Research, available at http://www.internettime.com/itimegroup/Goldman\%20Sachs\%20e-Learning\%20initiating\% 20report\%20-\%20July\%2025\%202000.pdf (accessed on 20 February 2012). 
Dumitrescu, A. (2009) Women Dominate PC Gaming, Solitaire is the Most Played Video Game, Softpedia, available at http://news.softpedia.com/news/Women-Dominate-PC-GamingSolitaire-Most-Played-Videogame-109150.shtml (accessed on 30 May 2012).

Felder, R.M. and Silverman, L.K. (1988) 'Learning and teaching styles in engineering education', Journal of Engineering Education, Vol. 78, No. 7, pp.674-681, available at http://www4.ncsu.edu/unity/lockers/users/f/felder/public/Papers/LS-1988.pdf (accessed on 20 February 2012).

Hsiao, H-C. (2007) 'A brief review of digital games and learning', DIGITEL 2007: Proceedings of the 1st IEEE International Workshop on Digital Game and Intelligent Toy Enhanced Learning, 26-28 March, Jhongli, Taiwan, pp.124-129.

Ke, F. (2008) 'A case study of computer gaming for math: engaged learning from gameplay?', Computers \& Education, Vol. 51, No. 4, pp.1609-1620.

Lin, C-H. and Liu, E.Z-F. (2009) 'A comparison between drill-based and game-based typing software', Transactions on Edutainment, Vol. 3, pp.48-58, (LNCS 5940).

Lu, C., Chang, M., Kinshuk, Huang, E. and Chen, C-W. (2011) 'Usability of context-aware mobile educational game', Knowledge Management \& E-Learning, Vol. 3, No. 3, pp.448-477.

Pailing, M. (2002) 'E-learning: is it really the best thing since the sliced bread?', Industrial and Commercial Training, Vol. 34, No. 4, pp.151-155.

Papastergiou, M. (2009) 'Digital game-based learning in high school computer science education: impact on educational effectiveness and student motivation', Computers \& Education, Vol. 52, No. 1, pp.1-12.

Shang, J., Jong, M.S-Y., Lee, F-L. and Lee, J.H-M. (2007) 'A pilot study on virtual interactive student-oriented learning environment', DIGITEL 2007: Proceedings of the 1st IEEE International Workshop on Digital Game and Intelligent Toy Enhanced Learning, 26-28 March, Jhongli, Taiwan, pp.65-72.

Steinman, R.A. and Blastos, M.T. (2002) 'A trading-card game teaching about host defence', Medical Education, Vol. 36, No. 12, pp.1201-1208.

Sung, J-Y., Levisohn, A., Song, J-W., Tomassetti, B. and Mazalek, A. (2007) 'Shadow box: an interactive learning toy for children', DIGITEL 2007: Proceedings of the 1st IEEE International Workshop on Digital Game and Intelligent Toy Enhanced Learning, 26-28 March, Jhongli, Taiwan, pp.206-208.

Šisler, V. and Brom, C. (2008) 'Designing an educational game: case study of Europe 2045', Transactions on Edutainment, Vol. 1, pp.1-16.

Tan, J. and Biswas, G. (2007) 'Simulation-based game learning environments: building and sustaining a fish tank', DIGITEL 2007: Proceedings of the 1st IEEE International Workshop on Digital Game and Intelligent Toy Enhanced Learning, 26-28 March, Jhongli, Taiwan, pp.73-80.

Virvou, M., Katsionis, G. and Manos, K. (2005) 'Combining software games with education: evaluation of its educational effectiveness', Educational Technology \& Society, Vol. 8, No. 2, pp.54-65.

Werneck, E. and Chang, M. (2009) 'Where academics meet the real world: difficulties encountered when conducting a project for designing a game-based learning in a company', Edutainment 2009: Proceedings of the 4th International Conference on E-Learning and Games, 9-11 August, Springer Lecture Notes in Computer Science, Vol. 5670, pp.176-183, Banff, $\mathrm{AB}$, Canada.

Wu, W.M-C., Cheng, H.N-H., Chiang, M-C., Deng, Y-C., Chou, C-Y., Tsai, C-C. and Chan, T-W. (2007) 'AnswerMatching: a competitive learning game with uneven chance tactic', DIGITEL 2007: Proceedings of the 1st IEEE International Workshop on Digital Game and Intelligent Toy Enhanced Learning, 26-28 March, Jhongli, Taiwan, pp.89-98. 